\title{
Pathophysiology of ageing, longevity and age related diseases
}

\author{
Alexander Bürkle ${ }^{1}$, Graziella Caselli ${ }^{2}$, Claudio Franceschi ${ }^{3}$, \\ Erminia Mariani ${ }^{4} 5$, Paolo Sansoni ${ }^{6}$, Angela Santoni ${ }^{7}$, Giancarlo Vecchio ${ }^{8}$, \\ Jacek M Witkowski ${ }^{9}$ and Calogero Caruso*10
}

\begin{abstract}
Address: ${ }^{1}$ Department of Biology, Box X911, University of Konstanz, Konstanz, Germany, ${ }^{2}$ Department of Demographic Sciences, University "La Sapienza" of Rome, Rome, Italy, ${ }^{3}$ Department of Experimental Pathology and CIG - Interdepartmental Center "L. Galvani", University of Bologna, Italy, ${ }^{4}$ Immunology and Genetics Laboratory, Institute Codivilla-Putti, Bologna, Italy, ${ }^{5}$ Department of Internal Medicine and Gastroenterology of University of Bologna, Bologna, Italy, ${ }^{6}$ Department of Internal Medicine and Biomedical Sciences, University of Parma, Parma, Italy, ${ }^{7}$ Department of Experimental Medicine, University "La Sapienza" of Rome, Rome, Italy, ${ }^{8}$ Department of Cellular and Molecular Biology and Pathology, University of Naples Federico II, Naples, Italy, ${ }^{9}$ Department of Pathophysiology, Medical University of Gdansk, Gdansk, Poland and ${ }^{10}$ Immunosenescence Unit, Department of Pathobiology and Biomedical Methodologies, University of Palermo, Palermo, Italy

Email: Alexander Bürkle - alexander.buerkle@uni-konstanz.de; Graziella Caselli - graziella.caselli@uniroma1.it; Claudio Franceschi - claudio.franceschi@unibo.it; Erminia Mariani - marianie@alma.unibo.it; Paolo Sansoni - paolo.sansoni@unipr.it; Angela Santoni - angela.santoni@uniroma1.it; Giancarlo Vecchio - giancarlo.vecchio@unina.it; Jacek M Witkowski - jawit@sanus.amg.gda.pl; Calogero Caruso* - marcoc@unipa.it

* Corresponding author
\end{abstract}

Published: 2 August 2007

Immunity \& Ageing 2007, 4:4 doi:10.1 186/I742-4933-4-4

This article is available from: http://www.immunityageing.com/content/4/I/4

(C) 2007 Bürkle et al; licensee BioMed Central Ltd.

This is an Open Access article distributed under the terms of the Creative Commons Attribution License (http://creativecommons.org/licenses/by/2.0), which permits unrestricted use, distribution, and reproduction in any medium, provided the original work is properly cited.

\begin{abstract}
On April 18, 2007 an international meeting on Pathophysiology of Ageing, Longevity and AgeRelated Diseases was held in Palermo, Italy. Several interesting topics on Cancer, Immunosenescence, Age-related inflammatory diseases and longevity were discussed. In this report we summarize the most important issues. However, ageing must be considered an unavoidable end point of the life history of each individual, nevertheless the increasing knowledge on ageing mechanisms, allows envisaging many different strategies to cope with, and delay it. So, a better understanding of pathophysiology of ageing and age-related disease is essential for giving everybody a reasonable chance for living a long and enjoyable final part of the life.
\end{abstract}

\section{Background}

On April 18, 2007 an international meeting on Pathophysiology of Ageing, Longevity and Age-Related Diseases was held in Palermo, Italy. Several interesting topics were discussed. Here we summarize the most important issues.

\section{Cancer}

The majority of cases of cancer occur in patients over the age of 65. Cancer rates increase sharply with age in both sexes: the incidence of cancer is 12-36 times higher in individuals aged 65 years or older than in individuals aged 25-44 years, and 2-3 times more common than in persons aged $45-64$ years. It is worth noting that $70 \%$ of deaths attributable to all forms of cancer occur in men and in women aged 65 years or older, whereas 35\% cancer deaths in men and $46 \%$ of cancer deaths in women occurred in those aged 75 years or older. The relationship between ageing and cancer is similar for most forms of cancer, and it is well described by the multistage model of carcinogenesis. Therefore ageing might be considered not as a determinant of cancer per se, but as a surrogate marker of the duration of exposure to relevant carcinogenic factors [1]. On the other hand the relationship between cancer and inflammation have recently been revised and it 
has been suggested that the inflammatory cells and cytokines found in tumours are more likely to contribute to tumour growth and progression [2]. Moreover cancer susceptibility and severity may be associated with functional polymorphisms of inflammatory cytokine genes [1]. If genetic damage is the "match that lights the fire" of cancer, some types of inflammation may provide the "fuel that feeds the flames" [2]. Thus, the increased frequencies of cancer in ageing might be due to well-known proinflammatory status of ageing [3].

In the Symposium, the role of oncogenes in human cancer was highlighted by analysing human epithelial thyroid tumours deriving either from follicular or from parafollicular (C) cells. Follicular-cell derived tumours represent a wide spectrum of lesions, ranging from benign adenomas through differentiated, papillary and follicular carcinomas, and undifferentiated, anaplastic, carcinomas, thus providing a good model for finding a correlation between specific genetic lesions and histologic phenotype. Follicular adenomas frequently show the presence of mutations in one of the three ras genes, HRAS, KRAS, and NRAS. G stimulatory protein (gsp) and thyrotropin receptor (TSH$\mathrm{R}$ ) mutations are at the origin of hyperfunctioning benign tumours (toxic nodules and adenomas). The two different types of differentiated thyroid carcinomas exhibit not only different morphology, but also different behaviour and are associated with mutations in different oncogenes: papillary carcinoma with rearrangements of either the RET or TRK genes and follicular carcinomas with mutations of one of the three ras oncogenes. The p53 tumour suppressor gene is frequently associated with anaplastic thyroid carcinomas. RET is a paradigmatic example of how different mutations of a single gene can lead to different neoplastic phenotypes. Somatic rearrangements, often caused by chromosomal inversions, activate the oncogenic potential of RET in human thyroid papillary carcinomas. These lesions occur in almost $50 \%$ of papillary cancers and consist in the juxtaposition of the 3 ' tyrosine kinase domain of the RET gene which codes for a receptor protein not normally expressed in follicular cells with the 5 ' domain of ubiquitously expressed genes, giving rise to several types of RET/PTC, papillary thyroid carcinomas, chimeric genes. Such ubiquitously expressed genes provide the promoter and dimerization functions, necessary for the constitutive activation of RET/PTC proteins. RET germline point mutations are responsible of familial multiple endocrine neoplasia type 2 syndromes (MEN 2) represented by (a) Familial Medullary Thyroid Carcinoma (FMTC), (b) MEN2A and (c) MEN2B, a common feature of which is the medullary thyroid carcinoma, a malignant tumour derived from parafollicular C-cells. RET point mutations can also occur as a somatic event in sporadic medullary thyroid carcinomas and pheochromocytomas. The detailed knowledge of the specific RET mutations responsible for human thyroid tumours provides relevant tools for the clinical management of these diseases $[4,5]$.

\section{Immunosenescence}

In the elderly, many alterations in innate and acquired immunity have been described and viewed as deleterious, hence the term immunosenescence. On the other hand, immunosenescence is a complex process involving multiple re-organisational and developmentally regulated changes, rather than simple unidirectional decline of the whole function. However, some immunological parameters are often reduced significantly in the elderly and, vice versa good function is tightly correlated to health status. Recent observations indicate that immunosenescence is not accompanied by an unavoidable and progressive deterioration of the immune function, but is rather the result of a remodelling where some functions are reduced while others remain unchanged or are even increased. Importantly, age-related changes of the immune system are directly or indirectly involved in the well-known susceptibility of the elderly to infectious diseases, autoimmunity, and cancer and in the decreased responsiveness to vaccination. The same is true for the pathogenesis of the more relevant age-related diseases, such as cardiovascular and neurodegenerative diseases, diabetes, and osteoporosis. In fact, all these diseases share an important immune component implicated in their pathogenesis. In addition it appears that the innate compartment of the immune system is relatively well preserved during ageing in comparison to the more recent and sophisticated clonotypic compartment that exhibits more profound modifications $[3,6-8]$.

Senescence of clonotypic immunity is mostly the result of alterations to $\mathrm{T}$ cells. Lifelong chronic antigen load seems to be the major driving force of immunosenescence, which impacts on human lifespan by reducing the number of virgin, i.e. antigen-non experienced, T cells, and simultaneously fills the immunological space with expanded clones of memory and effector, i.e. antigenexperienced, T cells [9]. Such lifelong and chronic antigen load is responsible for the chronic inflammatory status that characterises ageing [3]. The progressive reduction of naïve $\mathrm{T}$ cells involving both $\mathrm{CD} 4+$ and $\mathrm{CD} 8+\mathrm{T}$ lymphocytes is paralleled by a concomitant increase of memory CD28- T cells expressing a senescent phenotype, i.e. progressive shortening of telomeres and reduced replicative capacity [10]. A second fundamental aspect of immunosenescence is the progressive age-related increase of a proinflammatory status represented by an increase of inflammatory cytokines and of inflammatory markers predictive of mobility and mortality $[11,12]$. This proinflammatory condition is referred to chronic antigenic load (bacteria, virus, fungi, toxins, mutated cells) that 
continuously stimulate innate immunity and seems to favour the onset of typical age-related diseases (atherosclerosis, dementia, osteoporosis, neoplasia) where immune and autoimmune factors play an important role [3].

It has been suggested that chronic viral antigenic stimulation could be responsible of age-related modifications of lymphocyte subsets including clonal expansion of viral antigen-specific CD8+ T cells expressing a memory phenotype and that can represent up to a quarter of the whole CD8+ T cell population [13]. In a recent study [14], frequencies and phenotype of CD8+ T cell have been evaluated in nonagenarians and centenarians by HLA-A2 and B7 tetramers that incorporated epitopes specific for Epstein-Barr Virus (EBV) and Cytomegalovirus (CMV). The data demonstrate that EBV and CMV induce quantitatively and qualitatively different CD8+ T cell responses in advanced age. The frequency and absolute number of CD8+ T cells specific for three EBV-epitopes were relatively low and mostly included within CD8+CD28+ cells. By contrast, $\mathrm{CMV}$ infection was characterised by variable numbers of CD8+ T cells specific for two CMV epitopes that, in some subjects, were strikingly expanded and did not express the CD28 molecule. In order to further clarify the roles of CMV infection and the host, 121 subjects aged 25-100 were recently studied: 18 subjects were seronegative and 103 seropositive for $\mathrm{CMV}$ infection. It was observed that the age-dependent reduction of naïve CD8+ $\mathrm{T}$ cells was accelerated in $\mathrm{CMV}+$ subjects while the decline of naïve CD4+ T cells was not modified by the CMV infection. The reduction of naïve CD8+ cells was accompanied by a progressive increase of effector CD8+CD28- cells particularly in CMV+ subjects. An age-dependent accumulation of CD4+CD28- cells was only observed in CMV+ subjects while these cells were virtually absent within CMV- subjects. Samples of peripheral blood mononuclear cells were stimulated with mixtures of peptides spanning the entire pp65 and IE-1 CMV protein and thereafter the responding cells, Interferon(IFN)- $\gamma+$, were recorded both among CD8+ and CD4+ T cells. At the functional level, an age-dependent accumulation of CMV-specific (IFN- $\gamma+$ ) CD8+ cells was observed while an increase of pp65-specific CD4+ cells was only observed within subjects over 85 years of age. The majority of CMV-specific CD $8+($ IFN- $\gamma+)$ and $25 \%$ of CD4+ (IFN- $\gamma+)$ expressed the cytotoxic degranulation marker CD107a (Sansoni et al., paper submitted). These data support the view that chronic CMV infection is responsible for profound modifications of the lymphocyte subsets not only involving CD8+ but also CD4+ T cells and probably concurring to the age-dependent proinflammatory status that accompanies the main of age-associated diseases.
The study of the human immune response in healthy elderly donors has shown that immunosenescence not only affects the $\mathrm{T}$ cell response, but also various aspects of innate immunity, and probably the most extensive studies on age associated alterations in the innate immune system have been directed toward Natural Killer (NK) cells. NK cells, together with polymorphonuclear cells and macrophages, are components of the natural immune system. They represent a primary host defence system because they are responsible for spontaneous killing of certain tumour cells and of virally infected cells. NK cells lack T cell receptors and are characterised by the membrane expression of CD56 and CD16. In addition, they display two alternative mechanisms of cytolysis: a direct spontaneous cytotoxicity against a variety of tumour cells and indirect Fc receptor-mediated cytotoxicity against antibody-coated targets (Antibody-Dependent Cell-mediated Cytotoxicity; ADCC). [15]. A balance of signals received from multiple activating and inhibitory receptors regulates their effector functions. These receptors allow NK cells to rapidly survey their environment for potentially dangerous cells. When an imbalance in signalling favours activation, secretion of cytokines and/or release of cytotoxic granules occurs. In humans, NKG2D is one of the activating receptors that is expressed on NK cells, T $\gamma \delta$ cells, and CD8 $\alpha \beta$ T cells. NKG2D recognises as ligands UL16binding protein 1 (ULBP1), ULBP2, ULBP3, ULBP4, and the MHC class I chain-related molecules, MICA and MICB. These NKG2D ligands are generally absent or expressed at low levels on most healthy cells, but can be induced by viral and bacterial infections. Several studies have focused on the ability of NK cells to regulate acquired immune responses through the production of Th1-type cytokines early during infection or through the activation of dendritic cells. In addition, by establishing co-cultures of NK- and antigen-activated T cells, it has been shown that human NK cells can be induced to secrete IFN- $\gamma$ in response to Interleukin(IL)-2 produced by activated $T$ cells. In contrast, much less has been reported about the physical interactions that may take place between NK cells and immune cells of acquired branch of the response, in particular CD4+ $\mathrm{T}$ cells. NK cells promote acquired immune responses through their production of type 1 and type 2 cytokines or chemokines. Secretion of these factors by activated NK cells influences the differentiation of B and T lymphocytes. Increasing evidence indicates that NK cells are also directly involved in dendritic cell maturation. By contrast, a potential role for direct cellcell interactions between NK and Tlymphocytes, in particular CD4+ $\mathrm{T}$ cells, has not been explored. It has provided evidence that activated human NK cells are able of promoting TCR-dependent proliferation of resting autologous peripheral blood $\mathrm{CD} 4^{+} \mathrm{T}$ cells by a process that involves co-stimulatory molecules of the immunoglobulin and tumour necrosis factor (TNF) superfamilies. These 
findings suggest a novel link between natural and acquired immune responses $[16,17]$.

In 1987 a quantitative analysis of cells expressing the NK phenotype demonstrated that circulating NK cells increase in the peripheral blood of healthy individuals over 70 years old, compared to young or middle-aged people [18]. The increase in NK cell numbers in the peripheral blood from elderly people is directly correlated with age and with a decreased number of T cells supporting the idea of a compensative increase in NK cells for a decreased cytolytic activity. The cytolytic activity displayed by peripheral blood lymphocytes must be roughly dependent on the relative proportion of the NK cells present in the sample. By contrast the cytolytic activity of NK cells following incubation with K562 cells was found to be similar between the elderly, extremely healthy subjects selected according to the SENIEUR protocol and young subjects, despite the twofold increased number of effector cells [18]. In any case, purified or cloned populations of NK cells showed a decreased cytolytic activity in the aged on a per cell basis. This was consistent with the finding that, following target binding, each CD16-positive cell from elderly donors exerts only about half of the cytolytic activity displayed by NK cells from young donors [19]. However, neither the binding of effector to target cells nor the effector cells content, distribution or utilisation of perforin were significantly different between young and old groups. Therefore some other factors must account for the decreased lytic activity found in NK cells from aged people. In fact, the ability of NK cells to transform a receptor-mediated signal into an effector response, which is linked to the ability to generate second messengers after K562 stimulation, does show a pronounced agerelated decrease. The major biochemical defect appears to be an age-related delay in PIP $_{2}$ hydrolysis and decrease in the levels of $\mathrm{IP}_{3}$ formation in old NK cells after K562 stimulation [20]. Since an essentially preserved density of surface receptors involved in recognition and adhesion on NK cells was observed during ageing and also a preserved ability of NK cells to form conjugates with target cells, signal transduction may be impaired at a step distal to the binding of receptors.

Increasing evidence has demonstrated that the immune, endocrine and nervous systems are closely integrated and communicate through circulating cytokines, hormones and neurotransmitters. Many hormones and micronutrients have an important influence on the homeostasis of the immune system and in maintaining the integrity of body composition. The age-related decrease in adipose tissue, muscle and bone mass together with an increased risk of malnutrition, vitamin and trace element deficiency are among the major factors implicated in the development of frailty syndromes and impaired resistance to infections in the elderly. NK cell number and cytolytic activity were significantly associated with serum concentrations of vitamin $\mathrm{D}$, and this association was consistent with the evidence that vitamin D supplementation in elderly subjects in vivo significantly modulated NK activity, increasing circulating levels of IFN- $\alpha$. Anthropometric parameters indicating fat reserves and muscle reserves were also directly correlated with NK cell number and activity, and fat indicators were linked to vitamin D [21]. A further remarkable finding is the strong correlation between the number of NK cells and serum concentrations of zinc, a key element in many homeostatic responses of the body, including oxidative stress and in many biological functions, including immune efficiency [22]. In addition, zinc-aspartate supplementation in subjects with low or borderline normal circulating zinc levels increased concentration of this ion and was able to upmodulate NK cytolytic activity (Mariani, unpublished observations), suggesting a conversion of the pro-inflammatory status (characterised by high levels pro-inflammatory cytokines and possibly chemokines) [23] into more balanced Th1/Th2 responses. Because of the close correlation between the degree of malnutrition and immunodeficiency in the elderly (increasing the risk of infection, as demonstrated by the high number of non-responders among undernourished aged subjects who received influenza vaccination), these results stress the paramount importance of nutritional evaluation in the clinical assessment of elderly people ([24], for an extensive review).

\section{Age-related inflammatory disease}

The individual rates of ageing for the whole organism or for any organ system may vary, depending on genetics, disease history, chance, etc. This is especially true for the immune system. Impaired homeostasis and function of the immune system (especially of the CD4+ lymphocytes as the hub immune cells) underlies or at least participates in the pathology of Alzheimer's disease (AD) and of rheumatoid arthritis (RA). Both diseases belong to those that accelerate ageing (shorten the lifespan) of the sufferers. The question arising is therefore if the CD4+ cells of RA and/or AD patients undergo an accelerated ageing themselves. The major functionalities of the $\mathrm{CD} 4{ }^{+}$lymphocytes are manufacturing of multitude of cytokines and periodical proliferation to make effector and memory clones. The CD4+ lymphocytes of RA patients are already known to exhibit certain features similar to those observed for these cells in the healthy elderly, including relatively short telomeres, decreased amount of surface CD28, decreased overall proliferation etc. To investigate the possibility of accelerated aging of $\mathrm{CD}^{+}$lymphocytes of RA and $\mathrm{AD}$ patients, a new flow-cytometric technique of studying lymphocyte proliferation has been utilised. This technique is, based on staining with Carboxyfluorescein Succinimidyl ester and extensive mathematical analysis of 
acquired data, that allows for better quantification of proliferating lymphocytes, as well as calculation of dynamic parameters of proliferation including the timing of the cycle itself and of the G0 $\rightarrow$ G1 transition time. It allowed to show that $\mathrm{CD} 4{ }^{+}$cells of RA patients (especially younger ones) do not differ in these respects form those of healthy elderly, corroborating with the idea of their accelerated ageing. At least one of these parameters (the length of the G0 $\rightarrow$ G1 transition phase) seems to be correlated with the level of CD28 expression of the lymphocytes' surface which, in turn, depends on the regulatory activity of the proinflammatory cytokine TNF. Also another gene, Klotho) (sometimes dubbed the 'ageing hormone') contains a putative TNF-responsive regulatory sequence. Following this trace it has been demonstrated that both the transcriptional activity of the gene and the cellular contents of Klotho protein is greatly reduced in the $\mathrm{CD}^{+}$cells of RA patients regardless from their chronological age, and similar to that seen in the cells of healthy elderly. Expectedly, an enzymatic $\beta$-glucuronidase activity ascribed to Klotho protein (supposedly involved in the hydrolysis of steroid glucuronides) is reduced in both the RA and healthy elderly $\mathrm{CD} 44^{+}$lymphocytes, which may participate in the pro-inflammatory status of both elderly and the RA patients $[25,26]$. Using the same methodology for the $\mathrm{CD}^{+}$cells of $\mathrm{AD}$ patients the quasi-opposite change was found. Namely, these lymphocytes show the values of the dynamic parameters of proliferation in vitro, including the cell cycle and the G0 $\ni$ G1 time resembling these of the cells from healthy young individuals, despite being drawn from typical, elderly AD sufferers. Apparently, the exposure to $\beta$-amyloid peptides seems to play the role in these different results obtained for $\mathrm{AD}$ cells, especially the numbers of divisions, proliferation index and the G0 $\rightarrow$ G1 time; interestingly, the $\mathrm{CD} 4{ }^{+}$cells of $\mathrm{AD}$ patients seem to react to the peptides more than these of healthy ones, suggesting possible role of different genetic background (the HLA?) as one of the reasons for difference. In summary, these data show that RA may be considered a case for accelerated aging of the $\mathrm{CD}_{4}^{+}$ lymphocytes, while $\mathrm{AD}$ is not, although $\mathrm{AD}$ lymphocytes do display a deviation from normal function (Witkowski, unpublished observations).

\section{DNA repair}

Half a century ago, when the free radical theory of aging was first proposed, the damaging effects of reactive oxygen species (ROS) were in the focus of attention and considered the single most important determinant of aging. Two decades later, however, the disposable soma theory of ageing redirected the attention to the potential impact of cellular maintenance and repair pathways that are both genetically and environmentally determined and are counteracting the damaging effects of ROS. In this context poly(ADP-ribosyl)ation, a DNA-damage driven posttrans- lational modification of proteins, is of particular interest. Poly(ADP-ribosyl)ation is catalysed by poly(ADP-ribose) polymerase-1 (PARP-1), with $\mathrm{NAD}^{+}$serving as substrate [27]. PARP-1 activation is triggered by DNA strand breaks, is functionally associated with DNA repair pathways and is a survival factor for cells under low to moderate levels of genotoxic stress. Over a decade ago, a positive correlation between poly(ADP-ribosyl)ation capacity of mononuclear blood cells with longevity of mammalian species was described [28]. The subsequent comparison of purified recombinant human and rat PARP-1 revealed that this correlation might be explained in part by evolutionary sequence divergence [29]. This view fits perfectly with recent results from the literature on different knockout mice defective for nucleotide excision repair genes, revealing a crucial role of DNA repair as a longevity assurance pathway. In order better to understand the role of DNA repair and of poly(ADP-ribosyl)ation in ageing, the Bürkle group has recently developed an improved method to quantify DNA strand breaks and DNA crosslink formation in living cells by an automated fluorescence-detected alkaline DNA unwinding (FADU) assay. They have also set up a new assay to monitor poly(ADP-ribose) formation in living cells by flow cytometry, based on an assay previously developed for permeabilised cells [30].

\section{Longevity}

The improvements of the social-environmental conditions, of medical care, and the quality of life caused a general improvement of the health status of the population and a consequent reduction of the overall morbidity and mortality, resulting in an overall increase of life expectancy. Around the 1970s, the progressive decline of mortality (1-2\% per year) in individuals over 80 years old has increased in all industrialized countries, so that the number of centenarians has augmented about 20-fold. Centenarians represent a cohort of select survivors who benefit from a delay in the onset of diseases that often cause mortality in the general population at significantly younger ages [31]. A body data collected on the genetics of human longevity, mostly resulting from studies on centenarians, indicates that the following: Centenarians and long-living sibpairs are a good choice for the study of human longevity, because they represent an extreme phenotype, i.e. the survival tail of the population who escaped neonatal mortality, pre-antibiotic era illnesses, and fatal outcomes of age-related complex diseases. The model of centenarians is not simply an additional model with respect to well-studied organisms, and the study of humans has revealed characteristics of ageing and longevity (geographical and gender differences, role of antigenic load and inflammation, role of mtDNA variants) which did not emerge from studies in animal model systems. All the phenotypic characteristics of nonagenarians and centenarians fit the hypothesis that ageing is a remodelling 
process where the body of survivors progressively adapts to internal and external damaging agents they are exposed to during several decades, largely unpredicted by evolution. Such a remodelling process, which can be considered a Darwinian process occurring at the somatic level within the framework of the evolutionary constraints established by evolution for $H$. sapiens as a species may explain why the same gene polymorphism can have different (beneficial or detrimental) effects at different ages. Demographic evidence suggests that longevity can be achieved by different combinations of genes, environment, and chance, in a pattern that may be quantitatively and qualitatively different in different geographic areas, and that population-specific genetic factors play a role in the longevity phenotype. The concomitant and integrated use of new in silico and high-throughput strategies will greatly accelerate the identification of new longevity genes in humans [32-36,3].

There is a widespread consensus that the existence of a greater or a lesser number of centenarians largely depends on mortality features between 80 and 100 years of age. In fact, lower mortality among this age group implies that more people should live until they are aged 100 or over. Hence, demographers apply an indicator of mortality between 80 and 100 years in order to define the longevity of a population and not, as is done elsewhere, the proportion of centenarians in the population. Sardinia, two second largest island of Italy, has drawn widespread interest because of the large number of centenarians and the existence of a geographical area where male mortality after 80 years is lower than anywhere else in the region and Italy
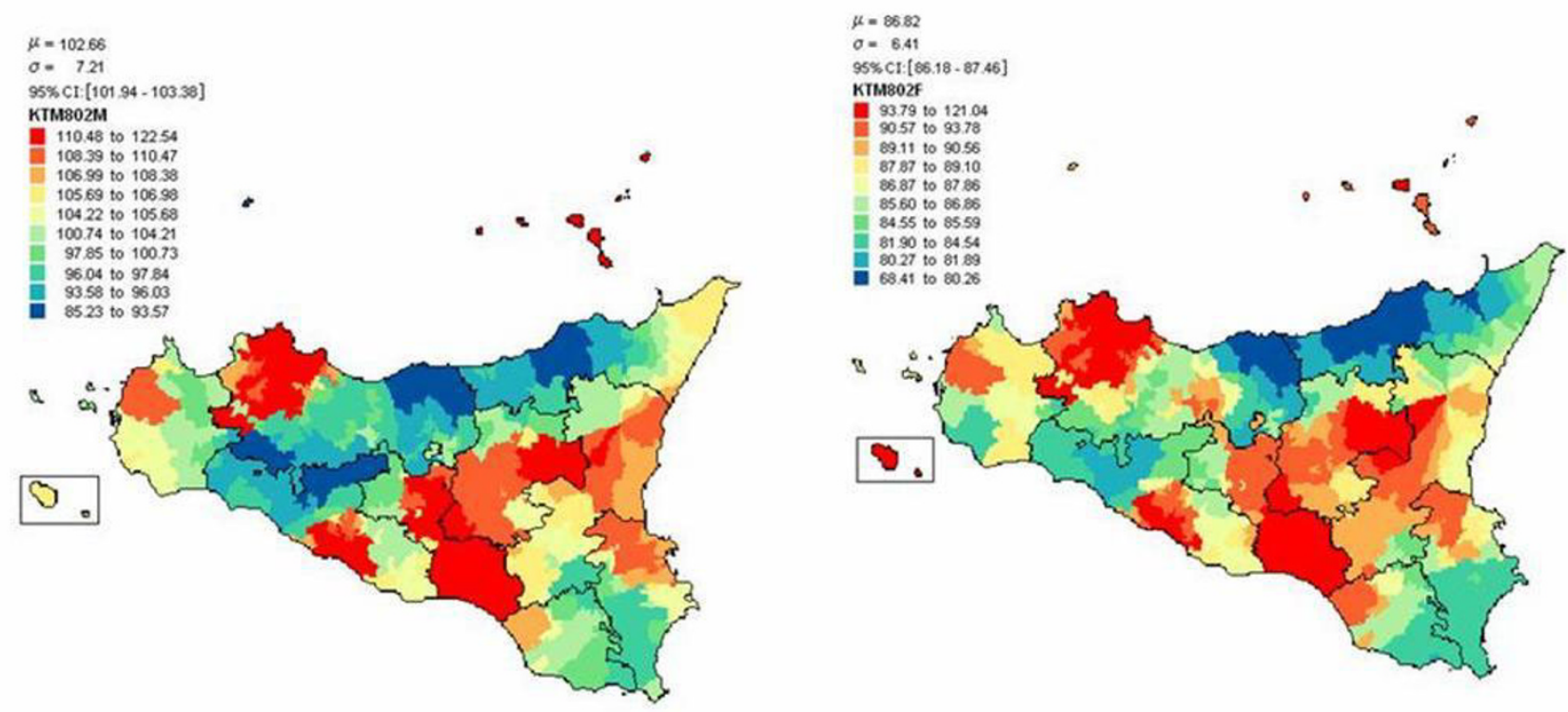

Figure I

Mortality in Sicily after age of 80 years: Male (left) Female (right) period 1994-200I (low mortality in blue, high mortality in red). For women in blue area the mortality is higher than in Italy. The municipalities concerned do not include polluted areas and are small, with the lowest number of inhabitants. 
$[37,38]$. This area covers various municipalities in the centre of the island, to the south of the province of Nuoro, where male mortality from cardiovascular diseases and cancers is especially low [39]. Focussing on genetically isolated populations, who are more homogeneous than the overall population with respect to cultural and historical background, origin and demographic parameters, is considered the most promising tool for the analysis and mapping of continuous multifactorial traits [40]. Once having seen the interesting outcome for Sardinia, it has turned focus to the largest island, Sicily, to see if something similar exists. The first aim was to identify geographic areas that are homogeneous with regard to low mortality of men and women after age 80 and to investigate the region-specific causes of death after this age. The second aim was to compare Sicily and Sardinia to see if there are some analogies and to find an explanation. Reference periods were 1981-1990 and 1991-2001. The 2001 census reports 390 municipalities in Sicily and 377 in Sardinia. The 386 and 363, respectively, selected here are geographically similar at the starting date of the municipal analysis (1981). Standardized mortality ratios (SMR) were calculated by municipalities (for all-cause and specific cause mortality) for ages 80 and over according to procedures applied in epidemiology. The Kernel density estimator is used to construct geographical maps. Kernel density estimators are the smoothed SMRs obtained as the spatial moving average for a number of municipalities adjacent to a given municipality. Results obtained highlight an area of longevity for men but not for women in Sicily with similar features to those found in Sardinia (Figure 1). In both cases the municipalities concerned do not include polluted areas and are small, with the lowest number of inhabitants. So, longevity concerns men living in a small town, without pollution, likely because of different working conditions, different life style i.e. reduced smoking and alcohol abuse and Mediterranean diet. Accordingly, these areas both in Sicily and in Sardinia also share low mortality from cancers and cardiovascular diseases. (Caselli \& Lipsi, unpublished observations). Longevity is reduced for women likely because of different women condition and different educational level which produce a different access to prevention or to health facilities. The reason because longevity has been observed particulary in small municipalities is not surprising. It is well established, in fact, that individuals with greater access to social support and family network have better health and lower levels of mortality, particularly when adult daughters are present.

\section{Conclusive remarks}

To conclude, ageing must be considered an unavoidable end point of the life history of each individual, nevertheless the increasing knowledge on ageing mechanisms, allows envisaging many different strategies to cope with, and delay it. So, a better understanding of pathophysiology of ageing and age-related disease is essential for giving everybody a reasonable chance for living a long and enjoyable final part of the life.

\section{Competing interests}

The author(s) declare that they have no competing interests.

\section{Authors' contributions}

$\mathrm{AB}$ carried out the molecular genetic studies on DNA damage, GC performed the demographic studies, CF and CC conceived the study on Ageing, longevity and inflammation, EM focused the attention on Cytokines and Chemokines, PS studied CD8+ and immunodeficiency in ageing, AS carried out assays on NK receptors and signalling, JMW on CD4+ and AD and RA and GV RET mutations in human thyroid tumours. All authors read and approved the final manuscript version.

\section{Acknowledgements}

The meeting organizer Prof. C. Caruso is deeply indebted to the other speakers and chairpersons of the meeting (Sebastiano Andò, Mario Barbagallo, Giuseppina Candore, Giuseppina Colonna-Romano, Pier Luigi Conaldi, Domenico Lio, Luigi Spicola) who contributed to the scientific success of the symposium. The collaboration with Alexander Bürkle is supported by a grant of Palermo University titled "HLA and other factors influencing individual life span" in order to strengthen international collaboration. In addition, the same day of the meeting the defence of $\mathrm{PhD}$ thesis of students belonging to the Pathobiology Department directed by $\mathrm{CC}$ was held. Prof. Caruso is proud of the hard and challenging work of his students (in particular Drs. Carmela Rita Balistreri, Florinda Listì and Sonya Vasto) which motivation and enthusiasm, with the management of Dr. Giuseppina Candore, have permitted to the whole Immunosenescence Unit to grow in the field of immunosenescence.

\section{References}

I. Caruso C, Lio D, Cavallone L, Franceschi C: Aging, longevity, inflammation, and cancer. Ann N Y Acad Sci 2004, 1028: I-I3.

2. Balkwill $F$, Mantovani $A$ : Inflammation and cancer: back to virchow? Lancet 200I, 357:539-45.

3. Vasto S, Candore G, Balistreri CR, Caruso M, Colonna-Romano G, Grimaldi MP, Listi F, Nuzzo D, Lio D, Caruso C: Inflammatory networks in ageing, age-related diseases and longevity. Mech Ageing Dev 2007, 128:83-9|.

4. Celetti A, Cerrato A, Merolla F, Vitagliano D, Vecchio G, Grieco M: $H 4(D I O S I 70)$, a gene frequently rearranged with RET in papillary thyroid carcinomas: functional characterization. Oncogene 2004, 23(I): 109-121.

5. Santoro M, Melillo RM, Carlomagno F, Vecchio G, Fusco A: Minireview: RET: normal and abnormal functions. Endocrinology 2004, | 45:5448-5।.

6. Pawelec G, Barnett Y, Forsey R, Frasca D, Globerson A, McLeod J, Caruso C, Franceschi C, Fulop T, Gupta S, Mariani E, Mocchegiani E, Solana R: T cells and aging. Front Biosci 2002, 7:d I056-d I I83.

7. Franceschi $\mathrm{C}$, Bonafe $\mathrm{M}$ : Centenarians as a model for healthy aging. Biochem Soc Trans 2003, 31:457-46I.

8. Vasto S, Caruso C: Immunity \& Ageing: a new journal looking at ageing from an immunological point of view. Immun Ageing 2004, I:I.

9. Fagnoni FF, Vescovini R, Passeri G, Bologna G, Pedrazzoni M, Lavagetto G, Casti A, Franceschi C, Passeri M, Sansoni P: Shortage of circulating naive CD8(+) $T$ cells provides new insights on immunodeficiency in aging. Blood 2000, 95:2860-8. 
10. Effros RB, Pawelec G: Replicative senescence of $\mathbf{T}$ cells: does the Hayflick Limit lead to immune exhaustion. Immunol Today 1997, I 8:450-4.

II. Ershler WB, Keller ET: Age-associated increased interleukin-6 gene expression, late-life diseases, and frailty. Annu Rev Med 2000, 5 I:245-70.

12. Harris TB, Ferrucci L, Tracy RP, Corti MC, Wacholder S, Ettinger WH Jr, Heimovitz H, Cohen HJ, Wallace R: Associations of elevated interleukin-6 and C-reactive protein levels with mortality in the elderly. Am J Med 1999, 106:506-12.

13. Khan N, Shariff N, Cobbold M, Bruton R, Ainsworth JA, Sinclair AJ, Nayak L, Moss PA: Cytomegalovirus seropositivity drives the CD8 $\mathrm{T}$ cell repertoire toward greater clonality in healthy elderly individuals. J Immunol 2002, I 69:1984-92.

14. Vescovini R, Telera A, Fagnoni F, Biasini C, Medici MC, Valcavi P, D Pede P, Lucchini G, Zanlari L, Passeri G, Zanni F, Chezzi C, Franceschi $C$, Sansoni P: Different contribution of EBV and CMV infections in very long-term carriers to age-related alterations of CD8+ T cells. Exp Gerontol 2004, 39:1233-1 243.

15. Palmieri G, Santoni A: NK receptors and signalling. Res Immunol 1997, I 48: 184-90.

16. Zingoni A, Sornasse T, Cocks BG, Tanaka Y, Santoni A, Lanier LL: Cross-talk between activated human NK cells and CD4+ $T$ cells via OX40-OX40 ligand interactions. J Immunol 2004, I 73:37|6-24.

17. Zingoni A, Sornasse T, Cocks BG, Tanaka Y, Santoni A, Lanier LL: NK cell regulation of $\mathbf{T}$ cell-mediated responses. Mol Immunol 2005, 42:45I-4.

18. Facchini A, Mariani E, Mariani AR, Papa S, Vitale M, Manzoli FA: Increased number of circulating Leu I I+ (CD I6) large granular lymphocytes and decreased NK activity during human ageing. Clin Exp Immunol 1987, 68:340-347.

19. Vitale M, Zamai L, Neri LM, Galanzi A, Facchini A, Rana R, Cataldi A, Papa $S:$ The impairment of natural killer function in the healthy aged is due to a post binding deficient mechanism. Cell Immunol 1992, I45: I- 10.

20. Mariani E, Mariani AR, Meneghetti A, Tarozzi A, Cocco L, Facchini A Age-dependent decreases of NK cell phosphoinsitide turnover durino spontaneous but not Fc-mediated cytolytic activity. Int Immunol 1998, 7:981-989.

2I. Mariani E, Ravaglia G, Forti P, Meneghetti A, Tarozzi A, Maioli F, Boschi F, Fratelli L, Pizzoferrato A, Piras F, Facchini A: Vitamin D: thyroid hormones and muscle mass influence natural killer (NK) innate immunity in healthy nonagenarians and centenarians. Clin Exp Immunol 1999, I I 6:19-27.

22. Ravaglia G, Forti P, Maioli F, Bastagli L, Facchini A, Mariani E, Savarino L, Sassi S, Cucinotta D, Lenaz G: Effect of micronutrient status on natural killer cell immune function in healthy free living subjects aged $\geq 90 y$. Am J Clin Nutr 2000, 7 I:590-598.

23. Mariani E, Cattini L, Neri S, Malavolta M, Mocchegiani E, Ravaglia G, Facchini A: Simultaneous evaluation of circulating chemokine and cytokine profiles in elderly subjects by multiplex technology: relationship with zinc status. Biogerontology 2006, 7:449-459.

24. Mariani E, Facchini A: Characterisation of NK cells in the elderly. In Advances in cell ageing and gerontology series, Basic biology and clinical impact of immunosenescence Volume 13. Edited by: Pawelec G. Elsevier BV, Amsterdam; 2003: I33-157.

25. Bryl E, Witkowski JM: Decreased proliferative capability of CD4(+) cells of elderly people is associated with faster loss of activation-related antigens and accumulation of regulatory T cells. Exp Gerontol 2004, 39:587-95.

26. Witkowski JM, Soroczynska-Cybula M, Bryl E, Smolenska Z, Jozwik A: Klotho - a common link in physiological and rheumatoid arthritis-related aging of human CD4+ lymphocytes. J Immunol I 78(2):77I-7. 2007, Jan I5.

27. Bürkle A, (Ed.): Poly(ADP-Ribosyl)ation. Landes Bioscience, Georgetown, TX, USA; 2006.

28. Grube K, Bürkle A: Poly(ADP-ribose) polymerase activity in mononuclear leukocytes of 13 mammalian species correlates with species-specific life span. Proc Natl Acad Sci USA 1992 , 89: I 1759-63.

29. Beneke S, Alvarez-Gonzalez R, Bürkle A: Comparative characterisation of poly(ADP-ribose) polymerase-I from two mammalian species with different life span. Exp Gerontol 2000, 35:989-1002.
30. Kunzmann A, Liu D, Annett K, Malaisé M, Thaa B, Hyland P, Barnett Y, Bürkle A: Assessment of cellular poly(APD-ribosyl)ation capacity by flow cytometry. Immunity \& Ageing 2006, 3:8.

3I. Candore G, Balistreri CR, Listi F, Grimaldi MP, Vasto S, ColonnaRomano G, Franceschi C, Lio D, Caselli G, Caruso C: Immunogenetics, gender, and longevity. Ann N Y Acad Sci 2006, 1089:5 I6-37.

32. Franceschi C, Olivieri F, Marchegiani F, Cardelli M, Cavallone L, Capri M, Salvioli S, Valensin S, De Benedictis G, Di lorio A, Caruso C, Paolisso G, Monti $\mathrm{D}$ : Genes involved in immune response/ inflammation, IGFI/insulin pathway and response to oxidative stress play a major role in the genetics of human longevity: the lesson of centenarians. Mech Ageing Dev 2005, | 26:35|-6|.

33. Franceschi C, Capri M, Monti D, Giunta S, Olivieri F, Sevini F, Panourgia MP, Invidia L, Celani L, Scurti M, Cevenini E, Castellani GC, Salvioli $S$ : Inflammaging and antiinflammaging: a systemic perspective on aging and longevity emerged from studies in humans. Mech Ageing Dev 2007, I 28:92- 105

34. Salvioli S, Olivieri F, Marchigiani F, Cardelli M, Santoro A, Bellavista E, Misto M, Invidia L, Capri M, Valensin S, Sevini F, Cevenini E, Celani L, Lescai F, Gonos E, Caruso C, Prolisso G, De Benedictis G, Monti D, Franceschi C: Genes, ageing and longevity in humans: problems, advantages and perspectives. Free Radic Res 2006, 40:1303-1323.

35. Capri M, Salvioli S, Sevini F, Valensin S, Celani L, Monti D, Pawelec G, De Benedictis G, Gonos ES, Franceschi C: The genetics of human longevity. Ann NY Acad Sci 2006, 1067:252-63.

36. De Benedictis G, Franceschi $C$ : The unusual genetics of human longevity. Sci Aging Knowledge Environ 2006, 2006( I 0):pe20.

37. Deiana L, Ferrucci L, Pes GM, Carru C, Delitala G, Ganau A, Mariotti S, Nieddu A, Pettinato S, Putzu P, Franceschi C, Baggio G: AKEntAnnos. The Sardinia Study of Extreme Longevity. Aging (Milano) 1999, I I: | 42-9.

38. Caselli G, Pozzi L, Vaupel JW, Deiana L, Pes G, Carru C, Franceschi C, Baggio G: Family clustering in Sardinian longevity: a genealogical approach. Exp Gerontol 2006, 4I:727-36.

39. Caselli G, Lipsi RM: Survival differences among the oldest old in Sardinia: who, what, where, and why? Demogr Res 2006 , I 4:267-294.

40. Zei G, Lisa A, Fiorani O, Magri C, Quintana-Murci L, Semino O, Santachiara-Benerecetti AS: From surnames to the history of $\mathbf{Y}$ chromosomes: the Sardinian population as a paradigm. Eur Hum Genet 2003, I I:802-7.

Publish with Bio Med Central and every scientist can read your work free of charge

"BioMed Central will be the most significant development for disseminating the results of biomedical research in our lifetime. "

Sir Paul Nurse, Cancer Research UK

Your research papers will be:

- available free of charge to the entire biomedical community

- peer reviewed and published immediately upon acceptance

- cited in PubMed and archived on PubMed Central

- yours - you keep the copyright

BioMedcentral 